\title{
Vegetation cover change and the driving factors over northwest China
}

\author{
ShengPei DAI ${ }^{1 *}$, Bo ZHANG ${ }^{1}$, HaiJun $\mathrm{WANG}^{2}$, YaMin WANG ${ }^{1}$, LingXia GUO ${ }^{1}$, XingMei WANG ${ }^{1}$, Dan $\mathrm{LI}^{1}$ \\ ${ }^{1}$ The College of Geography and Environmental Science, Northwest Normal University, Lanzhou 730070, China; \\ ${ }^{2}$ The Engineering and Technical College of Chengdu University of Technology, Leshan 614007, China
}

\begin{abstract}
In this paper the spatio-temporal variation of vegetation cover in northwest China during the period of 1982-2006 and its driving factors were analyzed using GIMMS/NDVI data. The annual average NDVI was increased with a rate of $0.0005 / a$ in northwest China and there was an obvious difference between regions. The trend line slopes of NDVI were higher than 0.0005 in the Tianshan Moutains and Altay Mountains of Xinjiang, the Qilian Mountains of Gansu and the eastern part of Qinghai, which indicated the vegetation cover was significantly increased in these areas. The trend line slopes of NDVI were lower than -0.0005 in the southern region of Qinghai, the border regions of Shaanxi and Ningxia, the parts of Gansu and Tarim Basin, Turpan and Tuoli in Xinjiang, which indicated the vegetation cover was declined in these areas. The NDVI of woodland, grassland and cultivated land had an ascending tendency during the study period. The study shows that the vegetation cover change was caused by both natural factors and human activities in northwest China. The natural vegetation change, such as forests was influenced by climate change, while human activities were the main reason to the change of planting vegetation. The changes of vegetation covers for different elevations, slopes and slope aspects were quite different. When the elevation is exceeded to $4,000 \mathrm{~m}$, the NDVI increasing trend was very low; the NDVI at the slope of less than $25^{\circ}$ was increased by the ecological construction; the variation of NDVI on sunny slope was stronger than that on shady slope. The temperature rose significantly in recent 25 years in northwest China by an average rate of $0.67^{\circ} \mathrm{C} / 10 \mathrm{a}$, and precipitation increased by an average rate of $8.15 \mathrm{~mm} / 10 \mathrm{a}$ after 1986 . There was positive correlation between vegetation cover and temperature and annual precipitation changes. Rising temperature increased the evaporation and drought of soils, which is not conducive to plant growth, and the irrigation in agricultural areas reduced the correlation between agricultural vegetation NDVI and precipitation. The improvement of agricultural production level and the projects of ecological construction are very important causes for the NDVI increase in northwest China, and the ecological effect of large-scale ecological construction projects has appeared.
\end{abstract}

Keywords: NDVI; vegetation cover; climate change; human activity; northwest China

\section{Introduction}

Vegetation is a bond that linkes soil, climatic, hydrologic and other elements in the whole ecosystem (Sun et al., 1998), but also an indicator of global climate change through carbon cycle (Li et al., 2008). Vegetation cover change is influenced by the climate change, human activity and atmospheric $\mathrm{CO}_{2}$ fertilization effect (Piao et al., 2006; Xin et al., 2007). As a sensitive parameter of surface vegetation cover and vegetation growth status, the normalized difference vegetation index (NDVI) has been used widely in the researches of vegetation cover change. NDVI is calculated by the formula: NDVI=(NIR-RED)/(NIR+RED), which uses the underlying principle that are characterized by high or low absorption of vegetation surface area, red (RED) and near-infrared (NIR) wavelengths, respectively (Tucker and Townshend, 1985). The NDVI was particularly sensitive to vegetation change in the areas with sparse vegetation, so it's very useful to analyze the vegetation change in northwest China (Li et al.,

Received 2010-09-25; accepted 2010-11-02 doi: 10.3724/SP.J.1227.2011.00025

* Corresponding author: ShengPei DAI (E-mail: daishengpei@yahoo.com.cn) 
2005). Many scholars have studied the relationship between vegetation NDVI and the climate factors. However, a few studies considered the impact of human factors (Gong et al., 2002; Nemani et al., 2003; Zhang et al., 2006a). Some research results showed that there are positive relationship between vegetation NDVI and temperature (Gong et al., 2002; Nemani et al., 2003; Li et al., 2008), and vegetation NDVI showed a significant positive correlation with precipitation seasonal changes (Tang and Chen, 2003). Precipitation is a limiting factor that restricts desert grassland growth in north China, and the response of vegetation to precipitation factor has a hysteresis effect (Li and Shi, 2000; Liu et al., 2009). The vegetation NDVI change caused by climatic factors showed significant spatial differences (Chen et al., 2001; Li et al., 2002). Some scholars have pointed out that vegetation cover change was influenced by both climate change and human activities (Xin et al., 2007; Yang et al., 2009). The improvement of agricultural production level and ecological construction increased vegetation NDVI, and the vegetation distribution was correlated negatively with GDP (gross domestic product) per square kilometer, population density and GDP per square kilometer on construction land, respectively (Han, 2007). Other studies showed that human activities were the important factor that impacted ecological environment change in arid areas in northwest China (Ma et al., 2006; Zhang et al., 2006b). Therefore, it can be revealed that the ecological environment change from the analysis between vegetation NDVI change and natural and human driving factors.

Under the condition of global warming, mainly in northwest China the climatic transformation from warm-dry to warm-wet happened in 1987 (Shi et al., 2003), and the air temperature was significantly high (Guo et al., 2005), and the precipitation was significantly increased in western Xinjiang (Hu et al., 2002) and the Qilian Mountains (Shi et al., 2003). At the same period, human activities such as agricultural activities, ecological construction were also constantly strengthened. In this paper, the spatio-temporal variation of vegetation cover in northwest China was analyzed under the background of above mentioned, and then the natural and human driving factors of the vegetation NDVI changes over northwest China were discussed.

\section{Study area}

The study area is located in the northwest of China between $49^{\circ} 10^{\prime} \mathrm{N}, 73^{\circ} 15^{\prime} \mathrm{E}$ and $31^{\circ} 32^{\prime} \mathrm{N}, 111^{\circ} 50^{\prime} \mathrm{E}$ (Fig. 1) with an area of approximately $3.5 \times 10^{7} \mathrm{~km}^{2}$ and the elevation ranging from -153 to $7,615 \mathrm{~m}$ a.s.l. The study area includes Xinjiang, Gansu, Qinghai, Shaanxi, Ningxia and western Inner Mongolia, China. Northwest China is main arid and semi arid areas in the mid temperate climate zone. The abundant light and heat resources, dry and strong evaporation, large temperature difference between day and night are the main climate features. It is of the most abundant sunshine and solar radiation in China. There is very low vegetation cover in most parts of northwest China. The capacities of vegetation to conserve soil water and to improve ecological environment are extremely weak. There are large areas of land desertification and dust-storms.

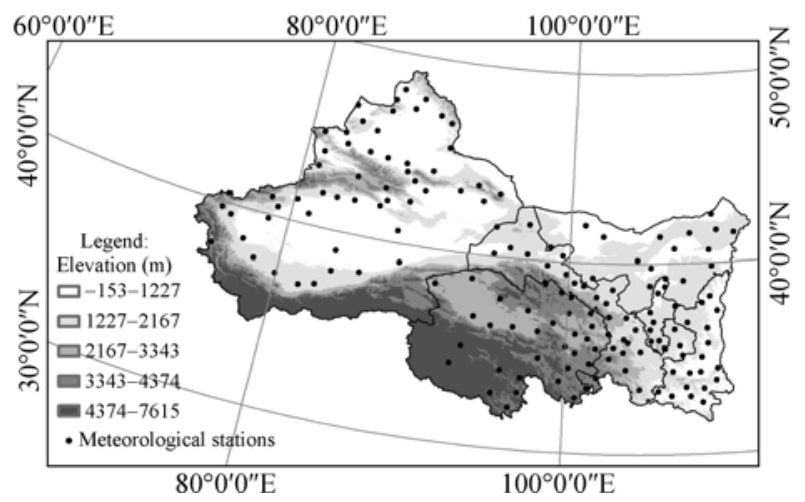

Fig. 1 The sketch of study area

\section{Materials and methods}

\subsection{Materials}

Data used in this study are as follows: (1) 15 days composed (maximum-value) NOAA/AVHRR VGTDN data from July in 1981 to December in 2006, with $8 \mathrm{~km} \times 8 \mathrm{~km}$ spatial resolution and stretched value ranging from 0 to 255 , which was downloaded from the internet database (Ma and Pan, 2007) and the atmospheric, radiometric and geometric correction had been done. True NDVI was restored with the formula $\mathrm{NDVI}=0.008 \times(\mathrm{DN}-128)$ in ArcGIS and the NDVI series with $8 \mathrm{~km} \times 8 \mathrm{~km}$ spatial resolution were obtained from July in 1981 to December in 2006. The 15 
days' NDVI as obtained in ArcGIS with northwest China as a whole. (2) Monthly temperature and precipitation data in 160 meteorological stations of northwest China from January in 1981 to December in 2006 were obtained from Climatic Data Center, National Meteorological Information Center, and China Meteorological Administration. (3) The topography and land use data were the $100 \mathrm{~m} \times 100 \mathrm{~m}$ spatial resolution DEM (digital elevation model) data and the $1 \mathrm{~km} \times 1 \mathrm{~km}$ spatial resolution land-use data in 2000 from the Environmental \& Ecological Science Data Center for West China. (4) The multi-year statistical data were obtained from the statistical yearbook during the period of 1949-2006 (National Bureau of Statistics of China, 1949-2006).

\subsection{Methods}

\subsubsection{Composition of monthly and annual average} NDVI

The monthly NDVI was obtained by 15 -days composed NDVI data with international practiced MVC (maximum value composed) method, i.e. the monthly NDVI image pixel value was replaced by the maximum NDVI values of two 15 days composed NDVI data in each month, and it can reduce the negative influence of atmospheric clouds, particles, shadows, perspective and solar altitude. So the monthly NDVI data from July in 1981 to December in 2006 were obtained with MAX command line in spatial analysis module in ArcGIS software. Then, the average method was used to composite the annual average NDVI, and the value of average NDVI was the representative of the most abundant vegetation period within a year, and the composed annual average NDVI eliminated the negative influence of seasonal changes of vegetation cover in different areas.

\subsubsection{Trend line analysis}

Trend line analysis can simulate the trend of each raster grid (Stow et al., 2003; Song and Ma, 2008), and reflect the spatial characteristics of vegetation cover change. The trend change can be calculated for a certain period and respective pixel by the method of linear regression of one variable, $y=\mathrm{a} x+\mathrm{b}$. Here, $x$ is the year number from 1 to 25 , and $y$ is the annual average NDVI value $\left(N D V I_{i}\right)$ for each year. We can use Eq. 1 to calculate the slope of the linear time trend by
OLS (Ordinary Least Squares) estimation in ArcGIS software spatial analysis module, and simulate the annual average NDVI change trend of northwest China from 1982 to 2006.

$$
\theta_{\text {slope }}=\frac{n \times \sum_{i=1}^{n}{ }_{i} \times N D V I_{i}-\sum_{i=1}^{n} i \sum_{i=1}^{n} N D V I_{i}}{n \times \sum_{i=1}^{n} i^{2}-\left(\sum_{i=1}^{n} i\right)^{2}},
$$

where $n$ is cumulative number of monitoring years. In our study $n$ is 25 , and $i$ is 1 for 1982, 2 for 1983 and so on. $\theta_{\text {slope }}$ is the slope of the linear regression of one variable equation. It is the average annual increase (or decrease) of NDVI from 1982 to 2006 . When $\theta_{\text {slope }}>0$, the average annual NDVI from 1982 to 2006 is increased, vice versa.

\subsubsection{Correlation analysis}

Correlation analysis is commonly used to analyze the relationship between inter-annual vegetation changes and climatic factors. Based on the location of 160 meteorological stations in northwest China, the annual average NDVI of each station was extracted to form the time series of annual average NDVI in ArcGIS from 1982 to 2006 . The correlation coefficients between annual average NDVI and temperature and precipitation for each station were calculated in SPSS software, and the spatial distribution map of the correlation coefficients was plotted.

\section{Results and discussion}

\subsection{Vegetation cover change over northwest China}

\subsubsection{Temporal variations of the annual average NDVI}

Figure 2a illustrates the annual average NDVI of northwest China from 1982 to 2006 . The slope of the linear regression trend-line is 0.0005 . Hence, it is an increase in lower range of an annual average NDVI, and the correlation coefficient between the annual average NDVI and the time was $0.40(P<0.05)$. But there are obvious undulating changes. From the inter-decadal variation point of view, three phases can be divided into: (1) the annual average NDVI of northwest China was slowly decreased excepted 1983 in the 1980s. (2) In the 1990s, the wave crests of the annual average NDVI occurred in 1993 and 1994, and the wave troughs occurred in 1995. (3) The annual 

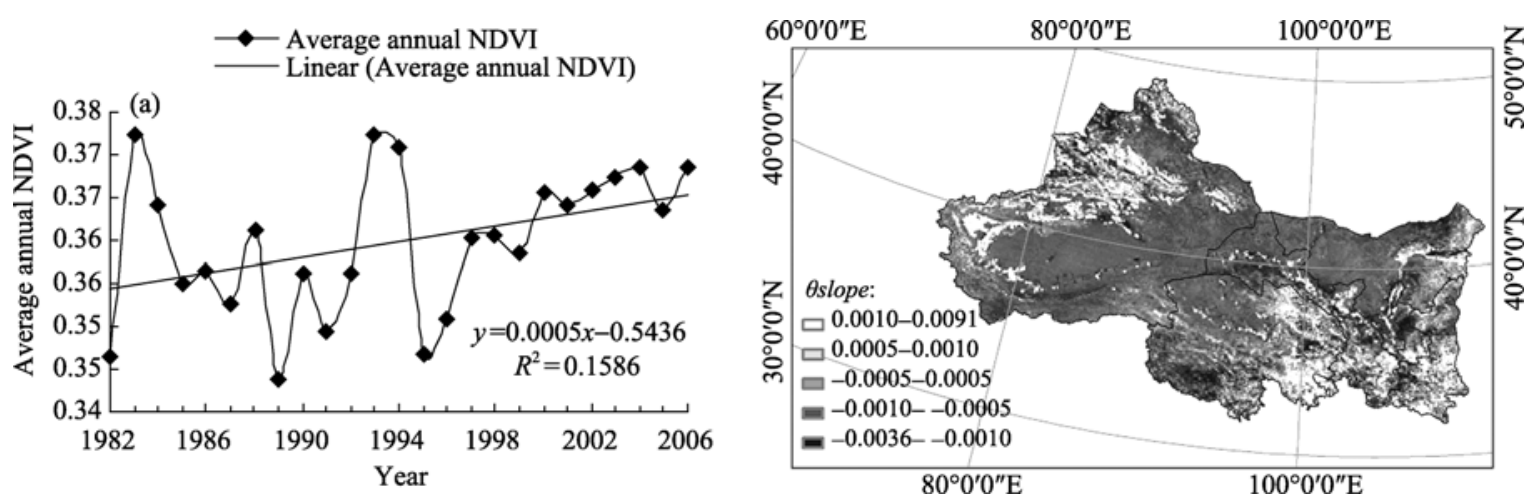

Fig. 2 Inter-annual variability of annual NDVI (a) and the trends of NDVI (b)

average NDVI was obviously increased after 2000. The slow increase of the annual average NDVI during recent 25 years (1986-2006) was also monitored in another study (Fang et al., 2004).

\subsubsection{Spatial variations of the annual average NDVI}

NDVI time series were the average of all the pixels in the study area, and it reflected the overall trend. However it can't show the significant spatial differences of vegetation NDVI changes. Therefore, the trend line analysis method is used to simulate the trend of each raster grid, and it reflects the spatial characteristics of vegetation cover change.

Figure $2 b$ is the spatial distribution map of the slope of the linear regression $\left(\theta_{\text {slope }}\right)$, which shows the vegetation NDVI changes over northwest China during 1982 to 2006. There is an obvious spacial difference, which is consistent with previous researches (Li et al., 2005; Song and Ma, 2008). The trend line slopes of NDVI were higher than 0.0005 in Tianshan and Altay Mountains of Xinjiang, the Qilian Mountains and Hexi areas of Gansu and the eastern and southeastern parts of Qinghai, which indicates that the vegetation cover is significantly increased in these areas. On the other hand, the trend line slopes of NDVI were lower than -0.0005 in the southern region of Qinghai, the border region of Shaanxi and Ningxia, the parts of Gansu and Tarim Basin, Turpan and Tuoli in Xinjiang, which indicates the decrease of the vegetation cover in these areas.

\subsection{Driving factors}

\subsubsection{Topography factors}

Topography factors such as elevation, slope, slope aspect and land use types are closely related to land cover types (Xin and $\mathrm{Wu}, 2007)$. Here, the elevation, slope and slope aspect were selected to analyze the vegetation NDVI change in different terrain conditions. The slopes of linear regression $\left(\theta_{\text {slope }}\right)$ were calculated in different elevations, slopes and slope aspects with $50 \mathrm{~m}, 0.5^{\circ}$ and $22.5^{\circ}$ for the equidistant which was based on $100 \mathrm{~m} \times 100 \mathrm{~m}$ spatial resolution DEM data and ArcGIS software.

Figure 3a shows the slope of the linear regression $\left(\theta_{\text {slope }}\right)$ in different elevations in northwest China. The increasing trend of the vegetation NDVI was low when the elevation was below $1,500 \mathrm{~m}$. But when the elevation was between $1,500 \mathrm{~m}$ and $4,000 \mathrm{~m}$, the vegetation NDVI has a marked increasing trend. When the elevation exceeded $4,000 \mathrm{~m}$, the increasing trend of NDVI was low again. The increasing trend changes of vegetation NDVI in different elevations may be related to the temperature and precipitation changes.

Figure $3 \mathrm{~b}$ shows the slope of the linear regression $\left(\theta_{\text {slope }}\right)$ in different slopes in northwest China. The vegetation NDVI in the agricultural cultivated areas at the slope of less than $5^{\circ}$ was obviously increased. The $\theta_{\text {slope }}$ was relatively steady about 0.0006 when the slope was between $5^{\circ}$ and $25^{\circ}$. The NDVI at the slope of less than $25^{\circ}$ was increased with the ecological construction in recent years. The vegetation NDVI increasing trend was very low when the slope exceeded $25^{\circ}$.

The geographical distribution and types of vegetation in cold and arid regions were influenced by the slope aspects that were determined by the solar radiation intensity, irradiation time, ground temperature, evaporation and other water-heat conditions. Simultaneously, vegetation also showed the differences in the capacity of resisting external interference (Zhou et al., 

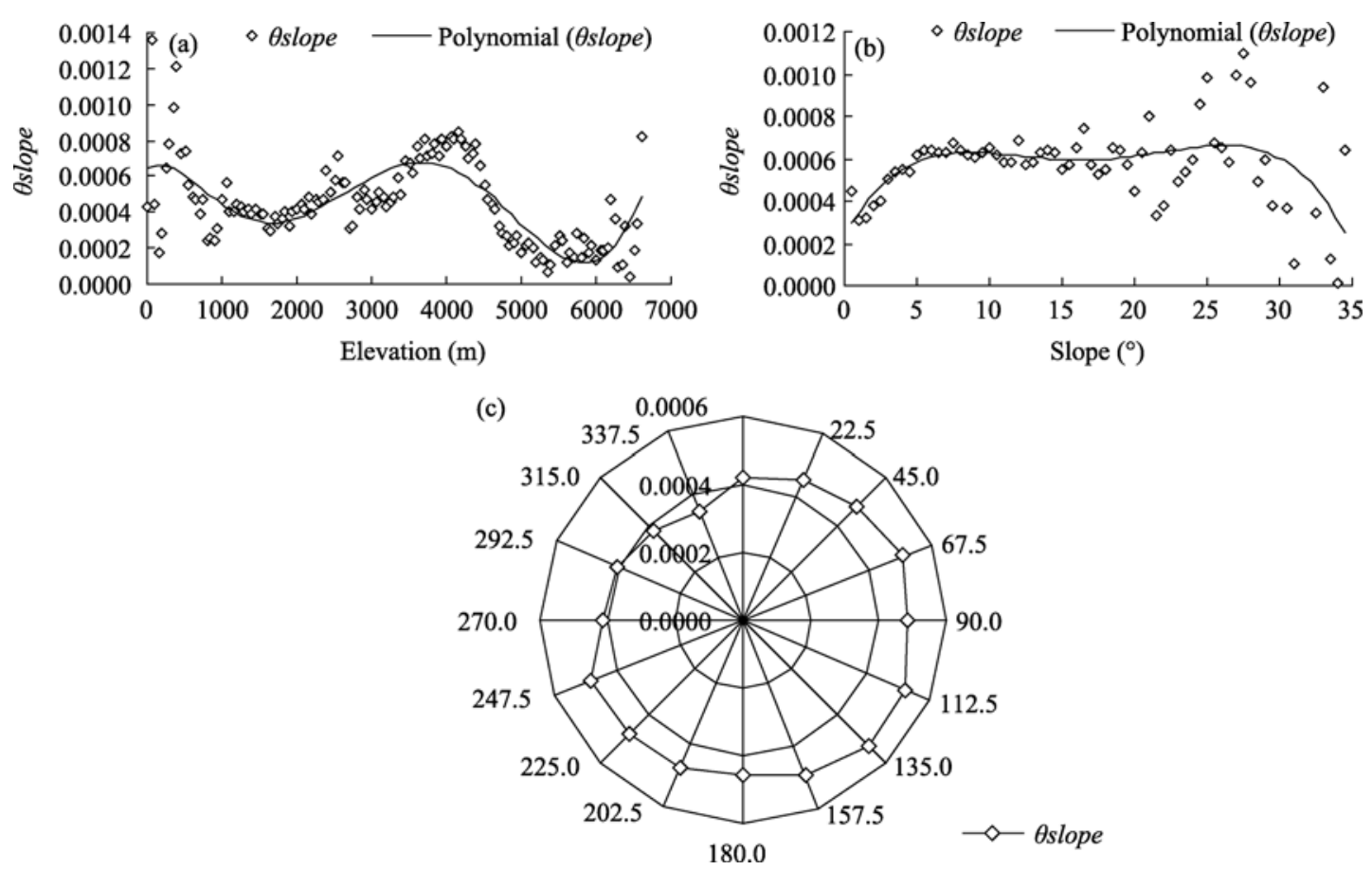

Fig. 3 The Variation of $\theta_{\text {slope }}$ in different elevations (a), slopes (b), slope aspects (c)

2004). The results in Fig. 3c showed that the NDVI change on the sunny slope was more active than that on the shady slope, and the $\theta_{\text {slope }}$ on the sunny slope (about 0.0005 ) was significantly greater than that on the shady slope $\left(\theta_{\text {slope }}<0.0004\right)$. The distances between sunny slope and shady slope are small and the rainfall conditions are similar. Therefore, the solar radiation is the main reason for the differences of vegetation change (Chen et al., 2008; $\mathrm{Li}$ and Liu, 2009).

\subsubsection{Climatic factors}

\subsubsection{Temperature}

Based on the meteorological data of 160 stations in the study area, the annual average temperature of northwest China was significantly increased with a linear growth rate of $0.67^{\circ} \mathrm{C} / 10 \mathrm{a}$ from 1982 to 2006 , and the correlation coefficients between the annual average temperature and the time was $0.81(P<0.001)$. Figure 4a shows the correlation coefficient between the annual average NDVI and the annual average temperatures, and indicates that the vegetation NDVI and temperatures are weak positive correlation, especially in cold regions. For example, the vegetation NDVI change was mainly caused by temperature in the Qilian Mountains of Gansu, the central parts of Qinghai, the Tianshan and Kunlun Mountains of Xinjiang and Qinling Mountains of Shaanxi (Wu et al., 2009). The annual average NDVI negatively correlates with the annual average temperature in the Junggar Basin of Xinjiang and the Loess Plateau because these areas are in arid or semi-arid ones with less precipitation. When air temperature exceeds the optimum temperature for plant growth, the RuBisCO (Ribulose bisphosphate carboxylase oxygenase) carboxylation reaction within plants will be greater than oxygenation, and then the net photosynthesis of plants decreased. At the same time, rising temperature increases evaporation and accelerates soil drought, which is not favor of plant growth in northwest China.

\subsubsection{Precipitation}

Study showed that the climatic change from warm-dry to warm-wet in northwest China happened in 1987 (Shi et al., 2003), and the precipitation was increased by an average rate of $8.15 \mathrm{~mm} / 10 \mathrm{a}$ after 1986. Figure $4 \mathrm{~b}$ illustrates the distribution map of the correlation coefficients between annual average NDVI and annual precipitations. The correlation between vegetation cover and annual precipitation changes were positive, because precipitation could be a major limiting factor for plant growth in arid and semi-arid areas over 

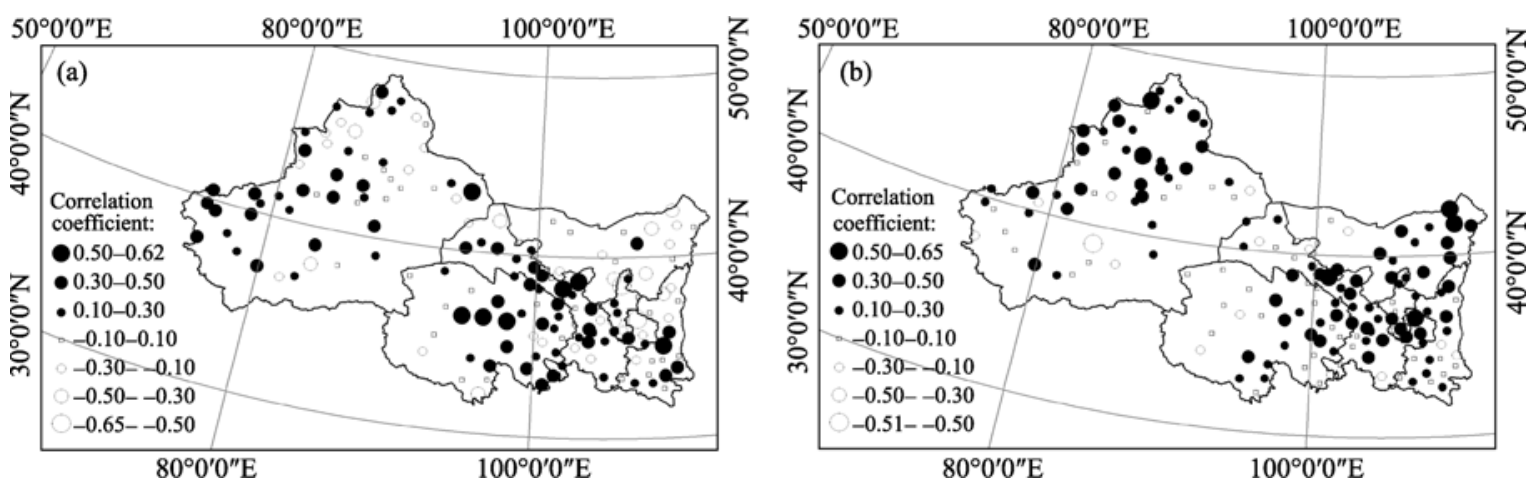

Fig. 4 The spatial distribution of correlation coefficient between NDVI and temperature (a); The spatial distribution of correlation coefficient between NDVI and precipitation (b)

northwest China. However, the correlation between vegetation cover and precipitation in irrigated agricultural areas and areas with sufficient precipitation was negative. For example, the NDVI was insensitive to precipitation in southern Gansu, western Qilian Mountain and Huashan, Tongchuan, Baoji of Shaanxi which may be attribute to the sufficient rainfall to the vegetation growth in these areas. However, in irrigated agricultural areas, grassland areas and sparse vegetation areas such as Tarim Basin of Xinjiang, the western Inner Mongolia and Qaidam Basin of Qinghai, the effect of precipitation to vegetation cover was not significant, and the irrigation of river water in these areas will reduce the correlation between agricultural vegetation NDVI and precipitation.

\subsubsection{Human activities}

Climatic factors significantly affect vegetation NDVI changes, but the continued strengthening human activity is also an important factor which can not be ignored. With the development of agricultural production and economy level and the concern to ecological environment, vegetation cover has great changes in the past decades (Xu et al., 2006). Because there are some difficulties to quantify human factors in vegetation cover change, the human driving factors of the vegetation cover change, such as land use, agricultural production and ecological construction over northwest China were analyzed.

\subsubsection{Land use}

Vegetations of different land use types are influenced by different natural and human factors. Therefore, the land-use data of $1 \mathrm{~km} \times 1 \mathrm{~km}$ spatial resolution in
2000 were used to calculate the vegetation NDVI changes in different land use types. In order to calculate and analyze conveniently vegetation NDVI, 15 land use types were selected (Table 1), which accounts for $92 \%$ of total study areas.

The standard of vegetation NDVI change was significant when the absolute $\theta_{\text {slope }}$ value was higher than 0.001 , and the areas and percentages of vegetation NDVI change in different land use types were calculated (Table 1). As a whole, the vegetation covers were increased in the study areas, and the vegetation NDVI significantly increased by $19.3 \%$ of the total area which is much greater than the degraded area (6\%). During the study period, the average annual NDVI of woodland, grassland and cultivated land increased. Cultivated land vegetation NDVI were increased remarkably, which raised the agricultural production level in recent years; the grassland vegetation NDVI increased with the development of ecological construction in recent years; and the woodland also showed an increasing trend in vegetation NDVI, which may be due to the increase precipitation (Shi et al., 2003). The natural vegetation (forests, etc.) change was influenced by climate change, while human activity was the main cause to the change of planting vegetation (cultivated land, etc.).

\subsubsection{Agricultural production}

In northwest China, irrigated agriculture is a main type. The vegetation NDVI changes in farming areas were greatly affected by human activities. For example, the irrigation in agricultural areas impacted the correlation between agricultural vegetation NDVI and pre- 
Table 1 Statistics of vegetation change for different land use types

\begin{tabular}{|c|c|c|c|c|c|}
\hline Land use types & $\begin{array}{c}\text { Total area } \\
\left(\mathrm{km}^{2}\right)\end{array}$ & $\begin{array}{l}\text { Increased area } \\
\left(\mathrm{km}^{2}\right)\end{array}$ & $\begin{array}{l}\text { Degraded area } \\
\qquad\left(\mathrm{km}^{2}\right)\end{array}$ & $\begin{array}{c}\text { Increased area } \\
(\%)\end{array}$ & $\begin{array}{c}\text { Degraded area } \\
(\%)\end{array}$ \\
\hline Forest land & 59,051 & 20,073 & 7,082 & 34.0 & 12.0 \\
\hline Shrub & 65,324 & 24,854 & 5,522 & 38.0 & 8.5 \\
\hline Open Forest Land & 32,435 & 11,263 & 3,025 & 34.7 & 9.3 \\
\hline High coverage grassland & 221,922 & 80,614 & 19,660 & 36.3 & 8.9 \\
\hline Moderate coverage grassland & 424,868 & 130,185 & 43,426 & 30.6 & 10.2 \\
\hline Low coverage grassland & 602,982 & 115,418 & 52,383 & 19.1 & 8.7 \\
\hline Sandy land & 549,731 & 28,389 & 8,659 & 5.2 & 1.6 \\
\hline Gobi & 486,497 & 34,935 & 19,960 & 7.2 & 4.1 \\
\hline Saline land & 97,740 & 12,184 & 3,753 & 12.5 & 3.8 \\
\hline Wetland & 26,081 & 7,555 & 1,665 & 29.0 & 6.4 \\
\hline Bare land & 28,108 & 2,938 & 1,760 & 10.5 & 6.3 \\
\hline Paddy field of plain area & 8,495 & 3,713 & 939 & 43.7 & 11.1 \\
\hline Dry farmland of plain area & 133,915 & 75,650 & 8,061 & 56.5 & 6.0 \\
\hline Dry farmland of hill area & 73,376 & 23,215 & 8,333 & 31.6 & 11.4 \\
\hline Dry farmland of mountain area & 24,515 & 9,790 & 1,729 & 39.9 & 7.1 \\
\hline Others & 624,704 & 87,748 & 23,051 & 14.0 & 3.7 \\
\hline Total & $3,459,744$ & 668,524 & 209,008 & 19.3 & 6.0 \\
\hline
\end{tabular}

cipitation ( $\mathrm{Xu}$ et al., 2007). The construction of water conservancy facilities for farmland irrigation and extensive use of fertilizer and pesticide made the impact of human activities on vegetation NDVI more marked. Figure 5 illustrates a steady increase of crop yield and the total sowing area of crops in northwest China since the 1980s, and kept a relatively stable high state in the late 1990s. The increases of crop yield and total sowing area result in the increase of vegetation NDVI (Fig. 5), especially in Tarim Basin of Xinjiang (Yang et al., 2009), Hexi Oasis and the Loop Plain's irrigation region of Inner Mongolia (Xin et al., 2007). The agricultural production strongly depends on irrigation not rainfall. Therefore, the impact of human activities must be included when analyzing precipitation effects on vegetation cover.

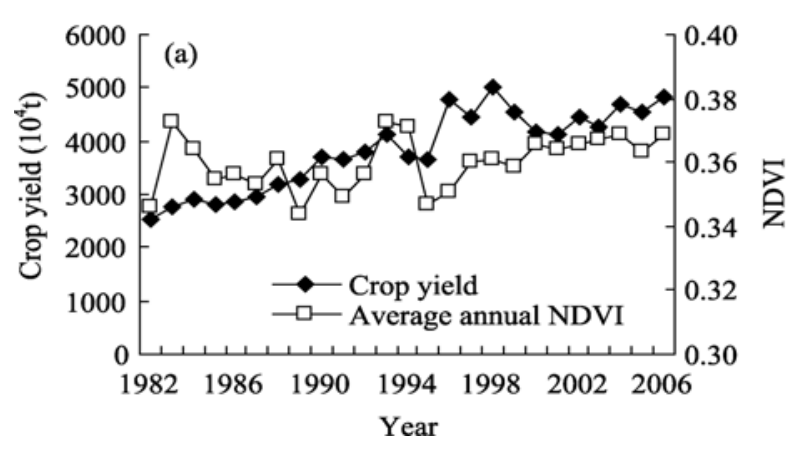

\subsubsection{Ecological construction project}

The Three-North Shelterbelt Project, which has been implemented since 1978, currently comes into the Stage IV of Phase II. According to the results of latest national forest inventory and desertification monitoring, the rate of forest coverage has reached up to $10 \%$; the desertified lands of nine provinces and the sandy desertified lands of six provinces have reversed, which has decreased to $40,925 \mathrm{~km}^{2}$ and $7,921 \mathrm{~km}^{2}$, respectively, compared with 1999 (http://news.sina.com.cn/c/ 2006-05-24/10339012296s.shtml). Since the ecological construction project in 1999, named Return Cultivated Land for Forest Land and Grass Land, the vegetation cover and the vegetation NDVI in northwestern China showed an increase trend at the same time. The

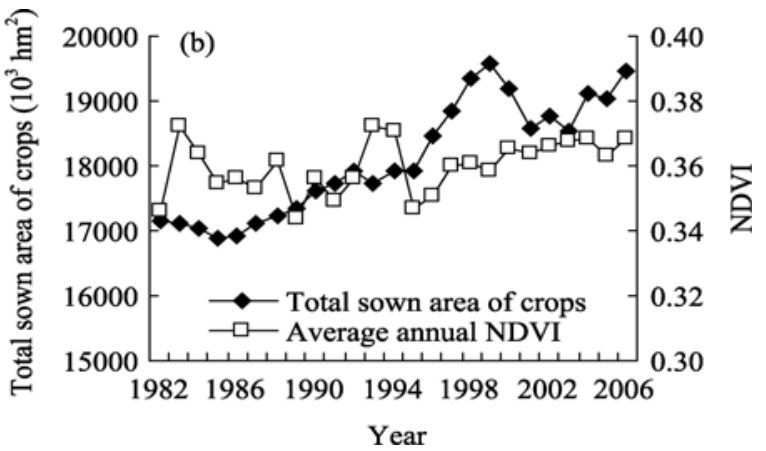

Fig. 5 Variations of crop yield (a), the total area of crops (b) and NDVI in northwest China 
correlation coefficient between the annual average vegetation NDVI and the time was $0.67(P<0.001)$ from 1999 to 2006. The vegetation NDVI was low with less precipitation from 1999 to 2001 in northwest China (Fig. 2a). The vegetation NDVI increased with an increasing precipitation since 2002, but the vegetation NDVI maintained an increasing trend while precipitation was relatively low from 2004 to 2005. This implies that the ecological effect of large-scale ecological construction projects has appeared.

\section{Conclusions}

In this paper the spatio-temporal variation of vegetation cover in northwest China during the period of 1982-2006 and the driving factors were analyzed using GIMMS/NDVI data. The main conclusions are as follows:

The annual average NDVI increased with a rate of $0.0005 / \mathrm{a}$ in recent 25 years over northwest China, but the annual average NDVI was slowly decreased in 1980s and increased after 1990s. There were obvious differences in different regions, and the trend line slopes of NDVI were higher than 0.0005 in Tianshan and Altay Mountains of Xinjiang, Qilian Mountains of Gansu and eastern Qinghai, which indicated that the vegetation cover was significantly increased. The trend line slopes of NDVI were lower than -0.0005 in the southern region of Qinghai, the border regions of Shaanxi and Ningxia, the parts of Gansu and the Tarim Basin, Turpan and Tuoli in Xinjiang, which indicated that the vegetation cover was decreased. The NDVI of woodland, grassland and cultivated land had an ascending tendency during the study period.

In recent 25 years, the temperature was significantly increased by an average rate of $0.67^{\circ} \mathrm{C} / 10 \mathrm{a}$ in northwest China, and the precipitation increased by an

\section{References}

Chen Y H, Li X B, Shi P J. 2001. Variation in NDVI driven by climate factors across China, 1983-1992. Journal of Plant Ecology, 25(6): $716-720$.

Chen T, Liang S H, Qian K Z, et al. 2008. Regularity and cause of vegetation coverage changes in the headwaters of the Changjiang River over the last 22 years. Earth Science Frontiers, 15(6): 323-331.

Fang J Y, Piao S L, He J S, et al. 2004. Increasing terrestrial vegetation activity in China, 1982-1999. Science in China Series C: Life Sciences, 47(3): 229-240. average rate of $8.15 \mathrm{~mm} / 10 \mathrm{a}$ after 1986 . The correlation between vegetation cover and temperature and precipitation changes was positive. Rising temperature increases the evaporation and soil drought, which is not benefit to plant growth, and the irrigation in agricultural areas reduced the correlation between agricultural vegetation NDVI and precipitation.

The results showed that vegetation cover change was caused by both natural factors and human activities in northwest China. The natural vegetation (forest, etc.) change was influenced by climate change, while human activity was the main cause of the change of planting vegetation (cultivated land, etc.). The vegetation cover changes for different elevations, slopes and slope aspects were quite different. When the elevation was exceeded to $4,000 \mathrm{~m}$, the NDVI increasing trend was very low; the ecological construction project increased the NDVI at the slope of less than $25^{\circ}$; the change of NDVI on the sunny slope was stronger than that on shady slope. The improvement of agricultural production level and ecological construction project are the very important causes for the increase of NDVI in northwest China, and the ecological effect of large scale ecological construction project has appeared.

\section{Acknowledgements}

This study was funded by the National Natural Science Foundation of China (40961038), the Knowledge Innovation Project of the Chinese Academy of Science (KZCX2-YW-Q10- 4), the Public Service Sector (Meteorology) Research Project (GYHY200806021-07), and the Provincial Key Subjects of Ecological Economy (5001-021). The authors thank the Environmental \& Ecological Science Data Center for West China and the Climatic Data Center, National Meteorological Information Center, China Meteorological Administration to provide the data sets. The authors would like to thank the anonymous reviewers and the editor for their insightful comments.

Gong D Y, Shi P J, He X Z. 2002. Spatial features of the coupling between spring NDVI and temperature over Northern Hemisphere. Journal of Geographical Sciences, 57(5): 505-514.

Guo Z M, Miao Q L, Li X. 2005. Change characteristics of temperature in North China since recent 50 years. Arid Land Geography, 28(2): $176-182$.

Han G F. 2007. Spatio-temporal change of vegetation cover in East China and influence of artifieial factors. $\mathrm{PhD}$ dissertation, East China Normal University, 1-161. 
Hu R J, Jiang F Q, Wang Y J, et al. 2002. A study on signals and effects of climatic pattern change from warm-dry to warm-wet in Xinjiang. Arid Land Geography, 25(3): 194-200.

Li X B, Shi P J. 2000. Sensitivity analysis of variation in NDVI, temperature and precipitation typical vegetation types across China. Journal of Plant Ecology, 24(3): 379-382.

Li X B, Chen Y H, Zhang Y X, et al. 2002. Impact of climate change on desret steppe Northern China. Advances in Earth Science, 17(2): 254-261.

Li X H, Shi Q D, Chang S L, et al. 2008. Change of NDVI based on NOAA image in northwest arid area of China in 1981-2001. Arid Land Geography, 31(6): 940-945.

Li Y C, Liu C X. 2009. Driving forces of the changes of land use/cover in northern China: 1987-2006. Arid Land Geography, 32(1): 37-46.

Li Z, Yan F L, Fan X T. 2005. The variability of NDVI over Northwest China and its relation to temperature and precipitation. Journal of Remote Sensing, 9(3): 308-313.

Li Z C, Wei Z G, Lv S H, et al. 2008. Variation characteristics of oasis vegetation in Central Hexi in the late 20th Century. Arid Land Geography, 31(1): 82-87.

Liu C L, Fan R H, Wu J J, et al. 2009. Temporal lag of grassland vegetation growth response to precipitation in Xilinguolemeng. Arid Land Geography, 32(4): 512-518.

Ma A Q, Gao F, Jia Y G, et al. 2006. RS-based study on the change of vegetation cover and its response to climate change in two desert marginal zones at both sides of the Helan Mountain. Arid Land Geography, 29 (2): 170-177.

Ma M G, Pan X D. 2007. Longterm vegetation index dataset of China-GIMMS AVHRR NDVI, [2010-01-04]. http://westdc. Westgis.ac.cn.

National Bureau of Statistics of China, 1949-2006. China Statistical Yearbook, 1949-2006. Beijing: China Statistics Press.

Nemani R, Keeling C, Hashimoto H, et al. 2003. Climate-driven increases in global terrestrial net primary production from 1982 to 1999. Science, 300: 1560-1563.

Piao S L, Anwar M, Fang J Y, et al. 2006. NDVI-based increase in growth of temperate grasslands and its responses to climate changes in China. Global Environmental Change, 16: 340-348.

Shi Y F, Shen Y P, Li D L, et al. 2003. Discussion on the present climate change from warm-dry to warm-wet in Northwest China. Quaternary Sciences, 23(2): 152-164.

Song Y, Ma M G. 2008. Variation of AVHRR NDVI and its relationship with climate in Chinese arid and cold regions. Journal of Remote
Sensing, 12(3): 499-505.

Stow D, Daeschner S, Hope A, et al. 2003. Variability of the seasonally integrated normalized difference vegetation index across the north slope of Alaska in the 1990s. International Journal of Remote Sensing, 24(5): 1111-1117.

Sun H Y, Wang C Y, Niu Z, et al. 1998. Analysis of the vegetation cover change and the relationship between NDVI and environmental factors by using NOAA time series data. Journal of Remote Sensing, 2(3): 204-210.

Tang H P, Chen Y F. 2003. Intra-annual variability of NDVI and its relation to climate in Northeast China transect. Quaternary Sciences, 23(3): 318-325.

Tucker C J, Townshend J R G. 1985. African land-cover classification using satellite data. Science, 227(4685): 369-375.

Wu Y F, Wang X F, Li M S, et al. 2009. NDVI changes under the spatial patterns driven by climates factors in China. Arid Land Geography, 32(2): 166-174.

Xin Z B, Xu J X. 2007. Spatial and temporal evolution of vegetation cover in the Loess Plateau and its response to climate change. Progress in Natural Science, 17(6): 770-778.

Xin Z B, Xu J X, Zheng W. 2007. Impact of climate change and human activities on the Loess Plateau in vegetation cover. Science in China Series D: Earth Sciences, 37(11): 1504-1514.

Xu J X. 2006. Effect of the changing rural socio-economic factors on sediment yield of the Jialingiiang River basin. Journal of Mountain Research, 24(4): 385-394.

Xu X K, Chen H, Zhang F. 2007. Temporal and spatial change of vegetation cover in the Northwest of China and factors analysis influencing on vegetations variation. Environmental Science, 28(1): 41-47.

Yang G H, Bao A M, Chen X, et al. 2009. Study of the vegetation cover change and its driving factors over Xinjiang during 1998-2007. Jounal of Glaciology and Geocryology, 31(3): 436-445.

Zhang J, Pan X L, Gao Z Q, et al. 2006a. Estimation of net primary productivity of the oasis-desert ecosystems in arid west China on RS-based ecological process. Arid Land Geography, 29(2): 255-261.

Zhang J, Zhang Q, Yang L H, et al. 2006b. Seasonal characters of regional vegetation activity in response to climate change in West China in recent 20 years. Journal of Geographical Sciences, 16(1): $78-86$.

Zhou A X, Ma Z Z, Zhou W C. 2004. Influences of slope and aspect on distribution and change of land use and cover in Daninghe river watershed. Journal of Soil and Water Conservation, 18(2): 126-129. 